\title{
MÉTODOS DE COMPILAÇÃO E COMPUTAÇÃO DE DADOS ESTATÍSTICOS DE DESEMBARQUE DE PESCADO NO PÔRTO DE SANTOS
}

(Recebido em 30/6/61)

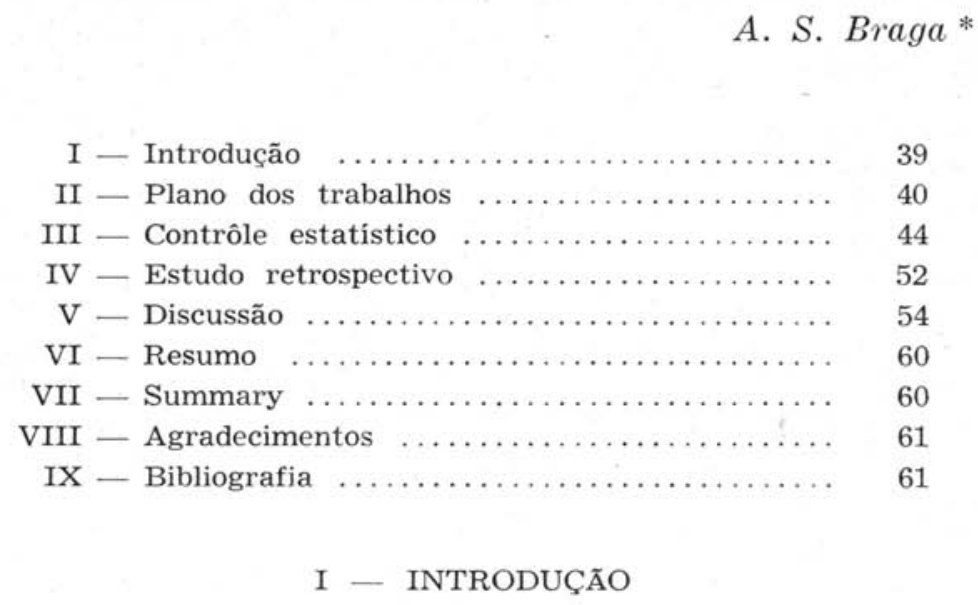

Há alguns anos, as autoridades nacionais vêm sentindo a necessidade de desenvolver racionalmente a exploração dos recursos marinhos de alimento, principalmente a indústria pesqueira.

Para isso, entretanto, tornou-se indispensável a elaboração de um programa de pesquisas sôbre a pesca, incluindo todos os aspectos do assunto, ou seja: estatístico, biológico e tecnológico.

No presente trabalho são feitas algumas explanações sôbre o desenvolvimento dêsse programa no Estado de São Paulo em 1958 e 1959. Incluiu-se, também, a revisão de alguns dados coletados anteriormente, em têrmos gerais, com a finalidade de mostrar o tipo de serviço atual, analisando-o comparativamente com os trabalhos efetuados em épocas anteriores.

A primeira dessas iniciativas teve lugar em 1944, ao ser instalada a Secção de Fauna Marítima na Divisão de Proteção e

* Departamento da Produção Animal da Secretaria da Agricultura. Membro do Grupo de Pesquisas sôbre a Pesca Maritima (G.P.P.M.).

Contr. n 15 do G.P.P.M. 
Produção de Peixes e Animais Silvestres, posteriormente extinta, de cuja gestão resultaram vários trabalhos de pesquisa (Vieira, et al., 1945).

Em 1950, em substituição a Secção de Fauna Marítima, e com as mesmas finalidades, criou-se naquela Divisão, o Serviço do Pescado. Como medida inicial, o nôvo órgão reorganizou os levantamentos estatísticos de desembarque em Santos, também parcialmente interrompidos em 1954, devido a dispensa da maioria dos servidores nêle lotados. Os trabalhos todavia continuaram, embora em rítmo menos acelerado, e os dados coligidos serviram de base aos estudos aqui realizados em 1955, por W. E. Ripley (1956), técnico da "Food and Agriculture Organization" (FAO).

$\mathrm{Na}$ fase atual, as perspectivas são mais favoráveis, de vez que as providências tomadas se caracterizam por medidas práticas, visando garantir a eficiência e continuidade dos trabalhos. Para tanto, considerada a necessidade de um perfeito entrosamento entre os órgãos estaduais que cuidam especialmente do assunto, resolveram os poderes públicos, estabelecer um convênio entre o Departamento da Produção Animal da Secretaria da Agricultura e o Instituto Oceanográfico da Universidade de São Paulo, para execução conjunta de um plano de pesquisas sôbre a pesca marítima.

O Grupo de Pesquisas sôbre a Pesca Marítima então formado com elementos de ambas as instituições, vem funcionando em Santos, na sede do Serviço do Pescado, desde julho de 1958, sob a orientação de I. D. Richardson, técnico da FAO.

\section{II - PLANO DOS TRABALHOS}

A distribuição e uniformidade das pesquisas se definiram através de um plano de trabalho prèviamente elaborado para ser desenvolvido à longo prazo, com o objetivo final de estabelecer para a pesca paulista um "ótimo de produção" e mantê-lo racionalmente.

A Figura 1 apresenta um esquema da sequiência dos trabalhos, salientando o perfeito entrosamento existente entre os seus diferentes setores. A apreciação do quadro, indica que teòricamente o plano traçado poderia ser dividido em duas fases distintas. A primeira envolvendo as pesquisas destinadas ao conhecimento das condições atuais de nossa pesca. A segunda sugerindo métodos e providências para corrigir as falhas porventura encontradas.

Nessas condições, portanto, o problema inicial da primeira fase era saber a quantidade de peixes disponível nas áreas em 


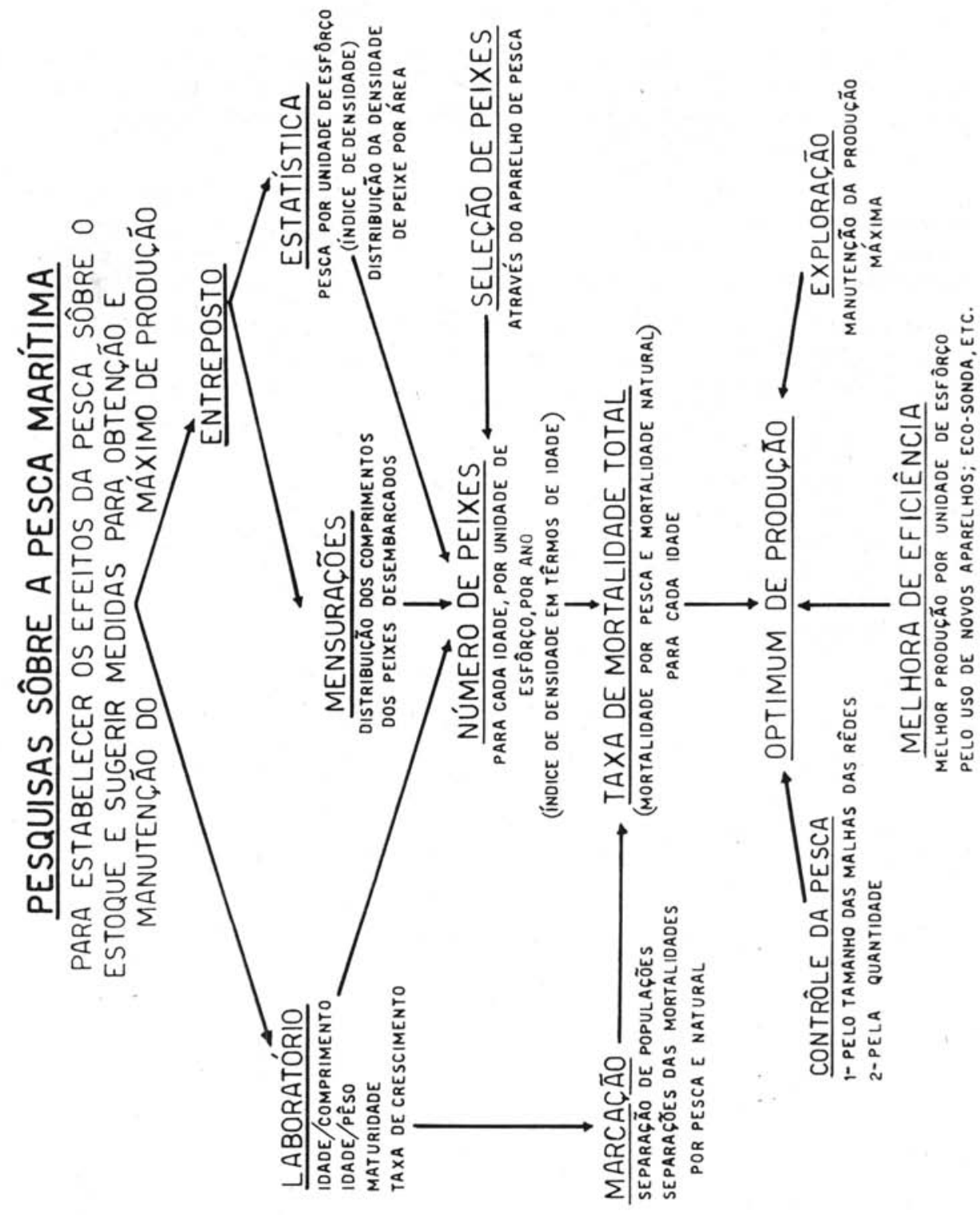


estudo. E para isso, foi indicado um levantamento do estoque existente nas águas onde opera nossa frota, em condições de ser capturado ao máximo, num determinado período, sem afetar o volume e a qualidade dos desembarques futuros.

Há vários processos para se pesquisar a quantidade de pescado numa certa área. A maioria dêles se baseia no uso de ecosondas, sendo conseqüentemente muito dispendiosos e impraticáveis no momento entre nós.

O grupo de Santos, entretanto, adotou um método prático e econômico já usado em outros países, o qual, não só permite a tabulação e o cálculo de distribuição das idades dos peixes, como. também, a avaliação da taxa de mortalidade infringida ao estoque.

O sistema adotado baseia-se na constância do trabalho individual e coletivo das embarcações de pesca, de cujos desembarques se calcula o número de peixes, para separá-los em populações e poder estimar a densidade relativa dos estoques nas áreas exploradas. A comparação da densidade atual disponível com a de períodos anteriores numa mesma área, considerando-se resultados obtidos com barcos e aparelhos de captura idênticos, poderá indicar maior ou menor resistência dos estoques alí existentes, aos efeitos da pesca. Em outras palavras: após alguns anos, será possível determinar se o volume de pescado na área estudada, diminuiu, estabilizou-se ou aumentou.

Quando a quantidade desembarcada por unidade de esfôrço no momento é menor que a dos anos anteriores, conclui-se ter havido um esfôrço de pesca superior à capacidade de recuperação dos estoques. Nesse caso deverão ser pesquisadas as verdadeiras causas de tal anormalidade, a fim de afastá-las em tempo hábil, quer pelo aumento das malhas das rêdes ou pela interdição provisória das áreas de captura afetadas, ou outras medidas indicadas para o caso.

Se entretanto, o volume das descargas por unidade de esfôrço permaneceu estabilizado durante vários períodos seguidos ou melhorou, isso significa que a pesca poderá ser mantida no mesmo rítmo ou intensificada.

A administração do estoque, visando a intensificação da pesca, todavia, deve ser efetuada de maneira bastante racional, encarando-se principalmente o lado econômico do problema.

Geralmente o aumento dos desembarques poderia ser conseguido através da introdução de novas unidades na frota e da melhoria da eficiência dos engenhos de captura existentes, ou de ambas as providências em conjunto. Porém, o que importa não é exclusivamente o conhecimento dessas medidas, e sim a forma e a 
oportunidade de sua aplicação, para se obter o máximo rendimento com menos gasto, dentro dos limites suportáveis pelo estoque.

De acôrdo com as diretrizes traçadas, ficou estabelecido que os elementos básicos necessários à realização das pesquisas, seriam obtidos na frota comercial que abastece o Estado, cujos integrantes passaram a figurar no plano traçado, como unidade de amostragem.

Realmente, o apreciável número e a variada categoria dos pesqueiros particulares permite-lhes operar concomitantemente em diversas áreas de pesca, com diferentes aparelhos de captura. Isto proporciona uma fonte permanente de observações técnicas, poupando aos poderes públicos, maiores investimentos e despesas decorrentes da aquisição e manutenção de uma frota própria.

A coleta dêsses dados, no entanto, acarretou maiores responsabilidades aos funcionários encarregados, uma vez que, o nôvo sistema adotado, obriga-os a reunir com a máxima fidelidade, tôdas as informações correspondentes a cada pescaria desembarcada, através de entrevistas com o mestre ou responsável pela embarcação.

Anteriormente, devido ao limitado número de servidores disponíveis as informações eram recolhidas por meio de impresso próprio, distribuido entre os pescadores, para ser por êles preenchido.

Essa prática apresentou certos inconvenientes oriundos em grande parte, do reduzido grau de instrução e ausência de conhecimentos técnicos que caracteriza a maioria dos profissionais de nossa frota.

As coletas de dados estatísticos deverão ser efetuadas através de funcionários especialmente habilitados, escolhidos entre os possuidores de conhecimentos gerais do assunto, até que a pesca nacional acuse maior desenvolvimento, atingindo em material humano e de trabalho, o mesmo nível alcançado em outros países. Além das peculiaridades comuns a outros centros, nossa indústria pesqueira apresenta certas características próprias, atuando, às vêzes, como fator negativo ao seu desenvolvimento normal. Tais inconvenientes, capazes de influir na qualidade das informações coletadas, poderão passar despercebidos ao observador menos avisado.

A presente publicação, tem como principal finalidade a apresentação de normas estabelecidas e aplicadas satisfatòriamente em nosso serviço, contribuindo bastante para o aperfeiçoamento e atualização das práticas até então empregadas na coleta de dados estatísticos de desembarque. O método aqui descrito, uma vez comprovada sua utilidade, poderá ser padronizado para uso nas demais bases nacionais de pesquisas de pesca. 
Na elaboração dêste trabalho foram incluidos dados referentes a vários anos. Os movimentos de 1958 (2. ${ }^{\circ}$ semestre) e 1959 têm maior expressão porque representam os primeiros levantamentos efetuados na nova fase de desenvolvimento das pesquisas, embora para os comentários destinados à apreciação de resultados, tenham sido tomados como base, ùnicamente os dados de 1959, pois nesse período funcionaram com maior eficiência e regularidade os serviços ligados ao setor.

Os dados referentes aos períodos anteriores a 1958, aqui incluídos, dão bem uma idéia dos elementos disponíveis na época servindo, ainda, para estabelecer comparações com a situação atual.

\section{III - CONTROLE ESTATÁSTICO}

Em atenção às exigências do nôvo sistema programado, tornou-se necessário reforçar e reestruturar a equipe encarregada da coleta e manipulação dos dados estatísticos.

O contrôle dos desembarques no pôrto de Santos, compreendendo sòmente a pesca motorizada, passou então a ser efetuado em três diferentes pontos de descarga:

a) Entreposto de Pesca

b) Bacia do Mercado

c) Cais do Macuco

Neste último local, descarregaram exclusivamente embarcações japonesas de maior porte, pertencentes a "Sociedade de Pesca Taiyo Ltda.". O movimento dêsses pesqueiros nos foi fornecido mensalmente, com todos os detalhes pela direção da emprêsa, em impresso próprio.

A Bacia do Mercado foi procurada por pequenos barcos que praticam a pesca de linha, nas ilhas de fora. Alguns sardinheiros também lhe deram preferência, pelo fato de alí estarem instalados comerciantes que exportam pescado para o interior do Estado, também conhecidos por "caixeteiros".

Finalmente, ao Entreposto de Pesca coube o maior volume de desembarques.

As condições de trabalho foram mais favoráveis no Entreposto de Pesca, local onde tivemos oportunidade de promover as instalações necessárias ao bom desempenho das atividades dos funcionários, através de duas salas localizadas próximas ao "pier", uma delas transformada em laboratório, cuja utilidade como setor 
avançado para coleta de dados e preparação das amostras foi perfeitamente demonstrada durante o desenvolvimento das pesquisas.

Na Bacia ou "Rampa do Mercado" o contrôle das descargas ofereceu bastante dificuldade, decorrente da menor organização reinante naquele próprio municipal. O local foi construído para atracação de canoas e pequenas embarcações, mas atendendo interêsses comerciais, os sardinheiros teimam em realizar alí seus desembarques, algumas vêzes em horas avançadas da noite.

A uniformidade dos levantamentos estatísticos no futuro depende muito das possibilidades de centralização das manobras de descarga. A duplicidade de contrôle exige elevado número de pessoal habilitado, encarece sobremaneira as atividades dos pesquisadores e os resultados nunca apresentam a mesma efetividade.

Salientamos, todavia, não ser possível nem necessário controlar todo o pescado capturado numa determinada área. Mesmo porque, em águas mais distantes do pôrto de Santos exploradas pelos barcos da frota paulista, operam também, embarcações de vários centros que desembarcam em diferentes pontos da costa, dentro e fora do Estado de São Paulo.

Isso, no entanto, não afeta em absoluto o resultado das pesquisas em andamento, de vez que, êsses estudos têm como finalidade, conhecer as tendências do estoque disponível no mar e não o levantamento total dos peixes desembarcados em todo o litoral do Estado.

Dêsse modo, o contrôle do desembarque das capturas obtidas por uma determinada quantidade de barcos (quantidade por unidade de esfôrço) é suficiente para se-poder avaliar a tendência do estoque.

Para maior facilidade e segurança no contrôle e anotação das informações técnicas e ocorrências verificadas durante as operações de captura, elaborou-se um impresso denominado "Contrôle Estatístico Diário" (modêlo n. ${ }^{\circ} 1$ ), para ser preenchido por funcionários durante as entrevistas com os mestres ou responsáveis pelas embarcações em descarga.

Informações complementares sôbre ocorrências gerais da pescaria, eram sempre que possível incluidas, destacando-se os dados referentes ao pescado rejeitado pelos "trawlers", de grande utilidade na correção estatística.

Diàriamente, os questionários eram submetidos à verificação e contrôle para se constatar, em tempo, quaisquer falhas porventura existentes sôbre as informações de determinado barco, enquanto o mesmo permanecia no pôrto em operações de abastecimento, ensejando, assim, se necessário, nova entrevista. 
Para demarcar as áreas de operação, utilizaram-se cartas marítimas de navegação, prèviamente quadriculadas em retângulos de um grau de longitude oeste e latitude sul, numeradas, formando blocos de aproximadamente 60 por 55 milhas náuticas na latitude de Santos. Assim, em substituição ao nome do local de pesca apontado pelo pescador, era anotado no impresso, apenas o número do bloco onde o mesmo recaisse. A partir de 1960, os blocos terão 10 minutos de lado, e conseqüentemente 10 milhas quadradas.

Ao anotarmos a duração de cada lance, foi levado em consideração o tempo de permanência do aparêlho de pesca (rêde) dentro d'água. Em relação às capturas com linha e espinhel o esfôrço foi calculado, levando-se em conta o tempo de permanência do barco fora do pôrto, além do número e comprimento das linhas, quantidade e tamanho de anzóis.

\section{Ficha Individual Mensal}

A necessidade de individualizar o movimento dos desembarques, levou-nos a elaborar um tipo de ficha (modêlo $n .^{\circ} 2$ ), para as quais se transportaram os dados individuais correspondentes a cada embarcação, de maneira análoga ao sistema utilizado pelos estabelecimentos bancários para contrôle de contas correntes de seus depositantes, cujo encerramento se faz mensalmente.

A nova fórmula adotada, veio ensejar a possibilidade de se conhecer com segurança, em qualquer data, o movimento parcial de desembarques efetuados por determinado barco. Além do mais, sendo comum o fato de alguns pesqueiros operarem com dois ou três diferentes aparelhos de captura numa só viagem, seu esfôrço era dividido em fichas correspondentes à cada engenho utilizado, possibilitando avaliar o volume de produção obtido com cada um dêles.

\section{Mapas Mensais e Anual de Produção}

Com o material coligido no encerramento das fichas individuais, foram organizados mapas mensais de produção. Pelo mesmo critério ao final do ano, computando-se os dados constantes nos relatórios mensais, elaborou-se um mapa anual.

Na confecção dos mapas mensais e anual, observou-se o critério de agrupar, tanto as embarcações como as espécies por elas capturadas, em ordem alfabética, considerando-se primeiro a produção por barco, mensalmente, em razão do aparêlho de pesca utilizado. A seguir, alinhou-se horizontalmente a numeração das diferentes áreas de pesca (blocos), de acôrdo com a respectiva loca- 
lização determinada pela latitude e longitude, relacionando-se, verticalmente, as variedades nelas capturadas. Os referidos dados constituem a base de tôdas as pesquisas sôbre a pesca marítima, já tendo sido utilizados em várias publicações feitas pelo grupo.

Devido ao seu excessivo tamanho, não foi possível a anexação neste trabalho, de um mapa mensal ou anual completo. Sua publicação se fará separadamente, cada ano, em forma de tabelas suficientemente detalhadas para aplicação imediata dentro do programa à longo prazo, elaborado para contrôle e administração do estoque.

$\mathrm{Na}$ discriminação nominal das espécies desembarcadas, adotou-se o mesmo critério que vem sendo posto em prática desde o início dos levantamentos estatísticos, em 1950. Desta forma seguiu-se a classificação comercial, conservando-se os nomes vulgares comumente empregados na determinação dos diversos tipos de pescado.

Nas Tabelas I e II, demonstrativas dos desembarques correspondentes a $1958\left(2 .^{\circ}\right.$ semestre) e 1959 , foram incluidas 60 variedades em 1958, com um total correspondente a 6.643,0 toneladas. Em 1959 anotou-se 73 diferentes peixes, englobando uma produção de $16.103,8$ toneladas.

A Figura 2, complementa as Tabelas I e II, estabelecendo um paralelo entre as produções mensais dos dois períodos.

Os números declarados referem-se ao pescado "fresco", tal como foi entregue ao consumo. Nêles não consta, por exemplo, a parte do produto utilizado como matéria prima nas fábricas e salgas instaladas em vários pontos de nosso litoral, ou ainda a produção da pesca individual (artesanal), quase sempre negociada diretamente pelo pescador, sem possibilidade de contrôle.

$\mathrm{Na}$ relação nominal das variedades, encontramos alguns nomes vulgares mal definidos, resultantes de manipulação realizada para atender interêsses comerciais:

a) Mistura - é um aglomerado de espécies de categoria inferior e valor comercial equivalente, vendidas em conjunto, por não compensar escolha.

b) Diversos - denominação usada pelos pescadores dos barcos japonêses, para definir, volume pequeno e heterogêneo de variedades menos interessantes, ou pouco comuns.

c) Tortinha - classificação comercial dada a exemplares jovens de pescada. Às vêzes o goete pequeno é incluido nesta denominação. 


\begin{tabular}{|c|c|c|c|c|c|}
\hline \begin{tabular}{l}
$\vec{T}$ \\
\multirow{2}{*}{} \\
0 \\
$H$
\end{tabular} & & 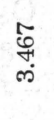 & $\begin{array}{l}\mathscr{0} \\
\vdots \\
\circ\end{array}$ & $\begin{array}{c}\infty \\
0 \\
\infty \\
\infty \\
\substack{++}\end{array}$ & 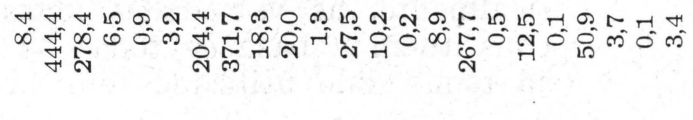 \\
\hline 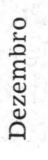 & \&్) & $\ddot{8}$ & 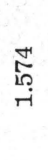 & $\begin{array}{l}0 \\
\& \\
0 \\
\oplus\end{array}$ & 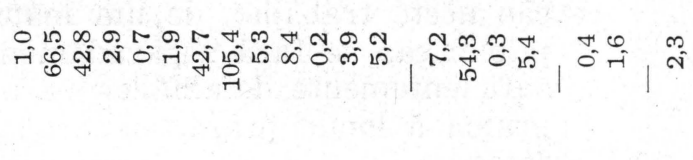 \\
\hline 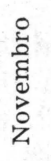 & $\underset{\sim}{\infty}$ & 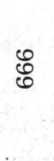 & 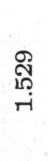 & 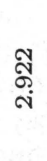 & 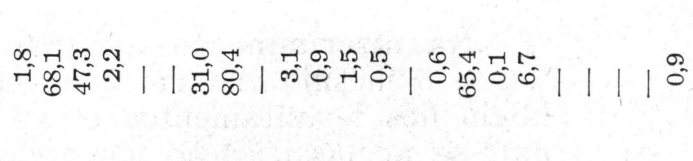 \\
\hline 紊 & สิ่ & สู่ & 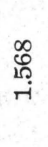 & $\begin{array}{l}\infty \\
\infty \\
\infty \\
\end{array}$ & 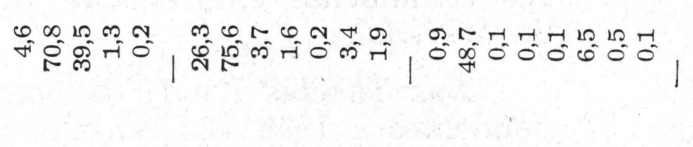 \\
\hline 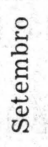 & $\tilde{\omega}$ & $\underset{\sim}{\mathcal{Q}}$ & $\begin{array}{l}\text { ळ్ } \\
\text { ri }\end{array}$ & 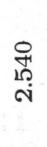 & 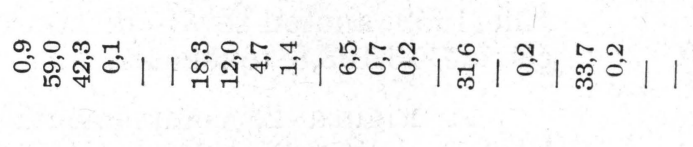 \\
\hline 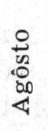 & 苛 & 品 & $\begin{array}{l}\vec{H} \\
\stackrel{\leftrightarrow}{\text { r }}\end{array}$ & 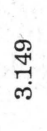 & 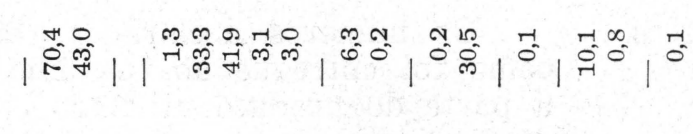 \\
\hline$\stackrel{\S}{\rightrightarrows}$ & 筩 & 周 & $\begin{array}{l}\text { స్ } \\
\text { กิ }\end{array}$ & $\begin{array}{l}\infty \\
\infty \\
\infty \\
\infty \\
\infty\end{array}$ & 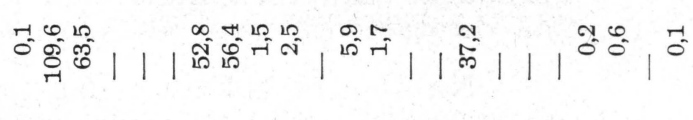 \\
\hline $\begin{array}{l}\infty \\
10 \\
0 \\
-1 \\
1\end{array}$ & 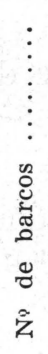 & 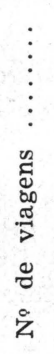 & 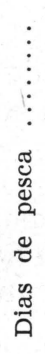 & 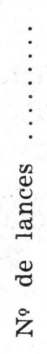 & 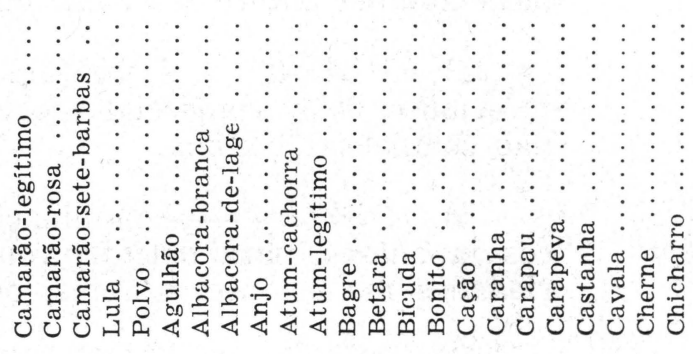 \\
\hline & & & & & H \\
\hline
\end{tabular}




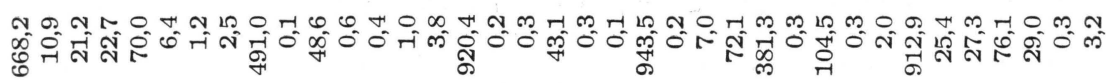




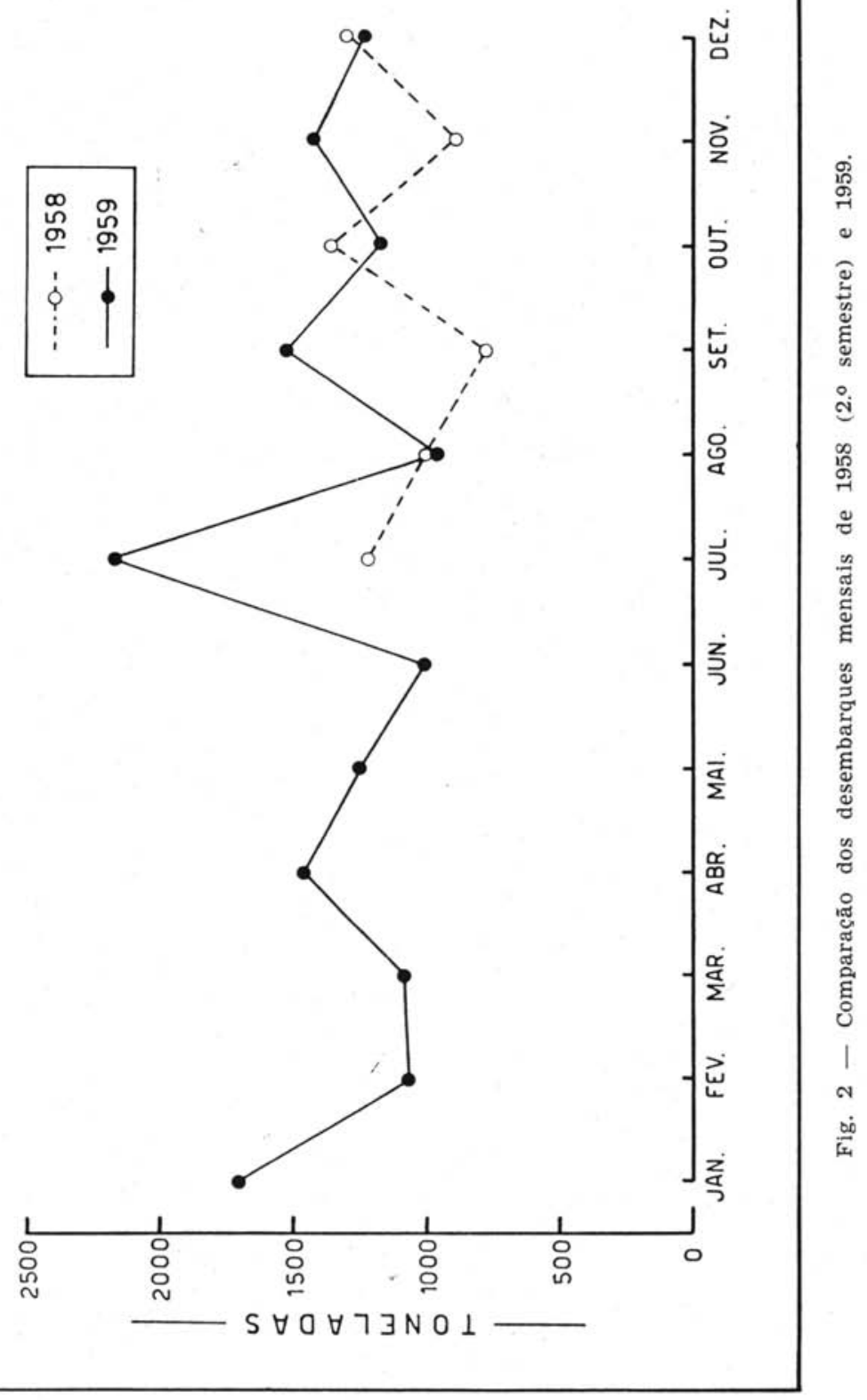


TABELA II - Movimento total de desembarque em Santos (toneladas)

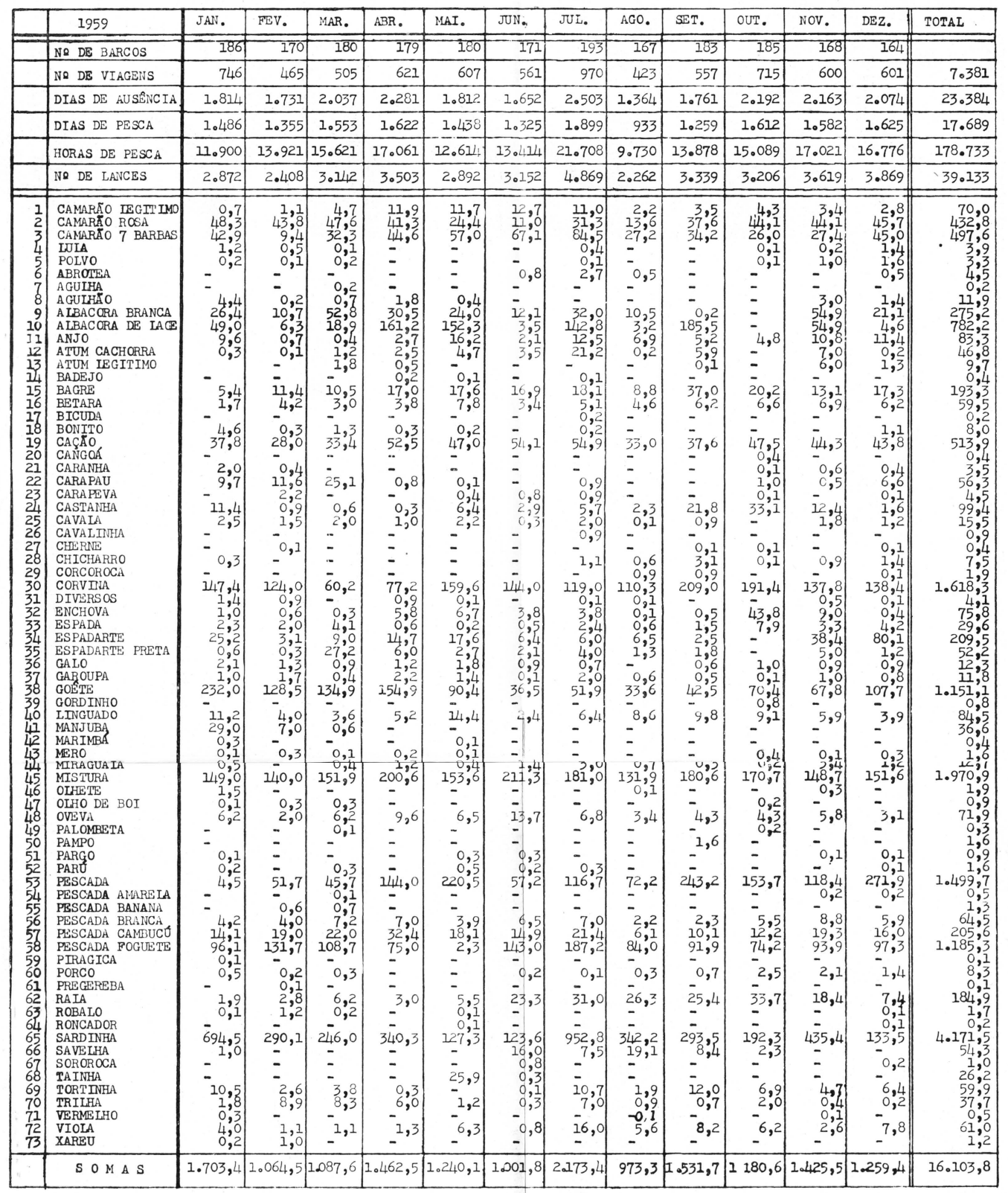


Embora os nomes de peixes relacionados em 1959 atingissem 73 unidades, verifica-se que em realidade um pequeno número teve participação mais efetiva nos desembarques, contribuindo com volume individual superior a cem toneladas anuais.

O quadro demonstrativo abaixo, relaciona por ordem de produção as dez variedades mais freqüentes, respectivas porcentagens e aparelhos de pesca utilizados na sua captura.

\begin{tabular}{|c|c|c|c|c|}
\hline $\begin{array}{l}\text { No de } \\
\text { ordem }\end{array}$ & Espécies ou variedades & $\begin{array}{l}\text { Desembar- } \\
\text { que - } 1959 \\
\text { (t) }\end{array}$ & $\%$ & $\begin{array}{c}\text { Aparêlho de } \\
\text { pesca }\end{array}$ \\
\hline $1^{\circ}$ & Sardinha-verdadeira . & $4.171,0$ & 25,9 & Traineira \\
\hline $2^{\circ}$ & Mistura $\ldots \ldots \ldots \ldots$ & $1.971,0$ & 12,2 & "Trawl" \\
\hline 3 & Corvina $\ldots \ldots \ldots \ldots$ & $1.618,0$ & 10,0 & "Trawl" \\
\hline 49 & Pescadinha...$\ldots \ldots$ & $1.500,0$ & 9,3 & "Trawl" \\
\hline $5^{\circ}$ & Pescada-foguete $\ldots$. & $1.185,0$ & 7,3 & "Trawl" \\
\hline $6^{\circ}$ & Goete...$\ldots \ldots \ldots$ & $1.151,0$ & 7,1 & "Trawl" \\
\hline $7^{\circ}$ & Albacora-de-lage $\ldots$. & 782,0 & 4,8 & Linha e espinhel \\
\hline $8^{\circ}$ & Cação $\quad \ldots \ldots \ldots \ldots$. & 514,0 & 3,1 & Linha e espinhel \\
\hline $9^{\circ}$ & Camarão-sete-barbas . & 498,0 & 3,0 & "Trawl" \\
\hline \multirow[t]{2}{*}{$10^{\circ}$} & Camarão-rosa $\ldots \ldots$. & 433,0 & 2,6 & "Trawl" \\
\hline & Total $\ldots \ldots \ldots \ldots$ & $13.823,0$ & 93,6 & \\
\hline \multirow[t]{2}{*}{$11^{\circ}$} & $\begin{array}{l}\text { Outras espécies ou va- } \\
\text { riedades }\end{array}$ & $2.281,0$ & 6,4 & Diversos \\
\hline & Total $\ldots \ldots \ldots \ldots$ & $16.104,0$ & 100,00 & \\
\hline
\end{tabular}

Os números representativos de pêso aqui apresentados, foram arredondados para a tonelagem mais próxima.

A análise dos dados, mostra as seis principais variedades, cujo desembarque ultrapassou de mil toneladas anuais, atingindo volume de descarga correspondente a $71,8 \%$ do movimento geral do ano.

Observando-se, a seguir, a situação das dez variedades, verifica-se terem elas uma significativa participação, correspondente a $85,3 \%$ dos desembarques, valendo salientar aí, o relativo índice alcançado pelos crustáceos, notadamente, a espécie conhecida como camarão-rosa, à vista do seu elevado valor comercial. 
Nessas condições, o movimento estatístico relativo à produção por variedades em 1959 poderá ser assim resumido.

\begin{tabular}{|c|c|c|}
\hline No de variedades & Produção (t) & $\%$ \\
\hline 10 & $13.823,0$ & 85,3 \\
63 & $2.281,0$ & 14,7 \\
\hline 73 & $16.104,0$ & 100,0 \\
\hline
\end{tabular}

Analisando-se ainda a situação das espécies e variedades mais freqüentes em 1959 em relação aos aparelhos de pesca utilizados, constatamos que a responsabilidade de captura dos peixes mais representativos, coube a três diferentes tipos de engenho, de acôrdo com o quadro abaixo:

\begin{tabular}{|c|c|c|c|}
\hline Aparelhos de pesca & $\begin{array}{c}\text { Producão } \\
(\mathrm{t})\end{array}$ & $\begin{array}{c}\text { No de espécies } \\
\text { ou variedades }\end{array}$ \\
\hline "Trawl” (Porta e Parelha) $\ldots \ldots$ & $8.356,0$ & 60,5 & 7 \\
Traineira $\ldots \ldots \ldots \ldots \ldots \ldots \ldots \ldots \ldots$ & $4.171,0$ & 30,2 & 1 \\
Linha e Espinhel $\ldots \ldots \ldots \ldots \ldots \ldots$ & $1.296,0$ & 9,3 & 2 \\
\hline Total $\ldots \ldots \ldots \ldots \ldots \ldots \ldots \ldots$ & $13.823,0$ & 100,00 & 10 \\
\hline
\end{tabular}

Os dados acima, ressaltam o maior volume de desembarque dos engenhos que operam de arrasto, na captura de peixes de fundo (tipo "trawl") e das rêdes de superfície coletoras de espécies pelágicas (traineiras). Os tipos de aparelhos conhecidos como "linha e espinhel" tiveram uma participação pouco expressiva.

\section{IV - ESTUDO RETROSPECTIVO}

Os primeiros trabalhos de contrôle estatístico de desembarque em São Paulo tiveram início no ano de 1942. Daquela época até 1946, todo o movimento da indústria pesqueira nacional estêve rigorosamente subordinado ao govêrno federal, através de uma autarquia especialmente criada: a Comissão Executiva da Pesca (C.E.P.) . 

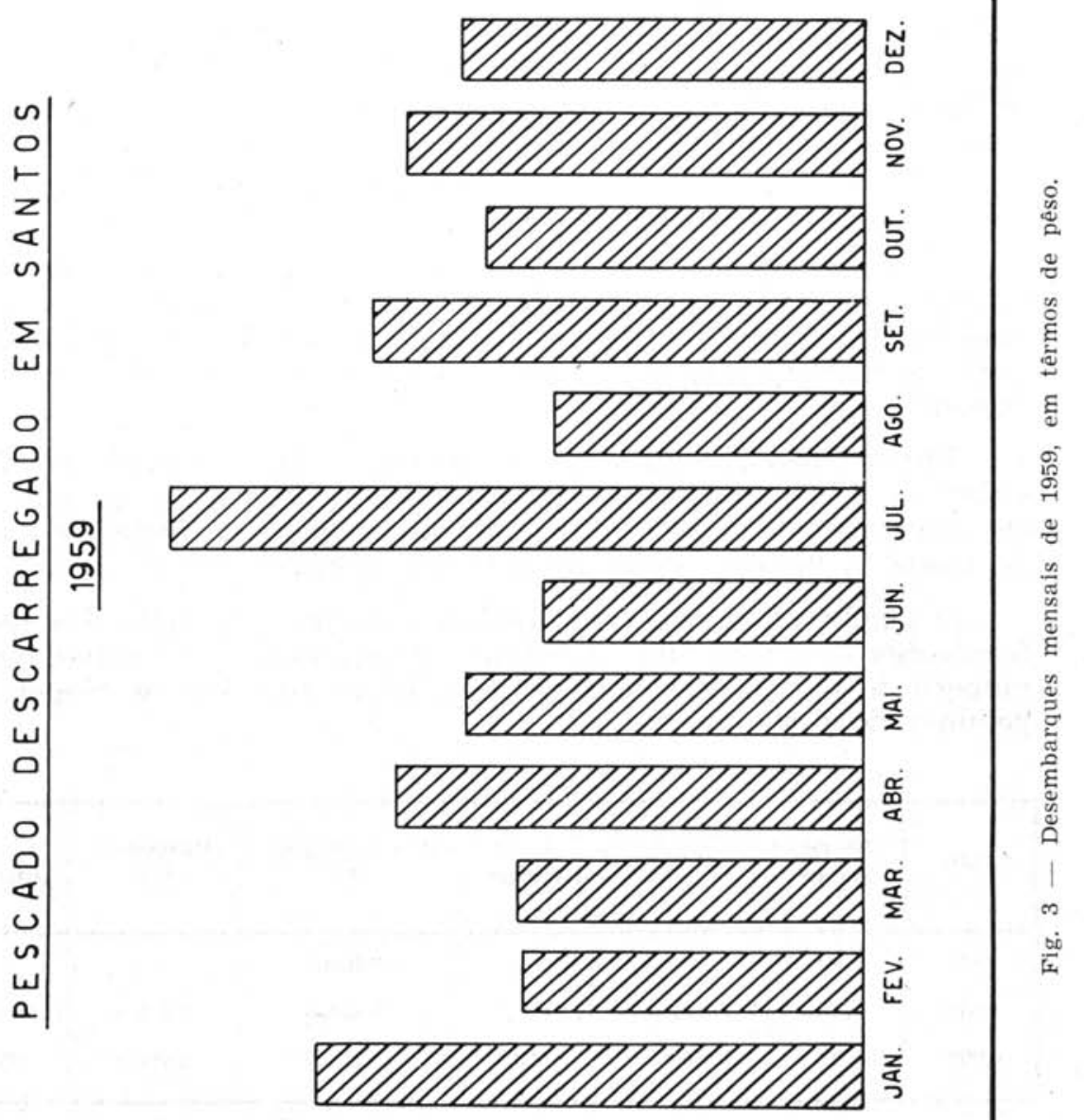
Os levantamentos estatísticos elaborados durante aquêle período englobavam a produção de todo o Estado. Posteriormente, com a extinção da C.E.P., o contrôle passou a ser feito exclusivamente sôbre as descargas efetuadas no pôrto de Santos.

Embora lentamente, a pesca paulista vem evoluindo com o decorrer dos anos, tendo as transformações ocorridas revelado algumas tendências adiante indicadas.

Com a finalidade de possibilitar a apreciação do seu desenvolvimento anterior e compará-lo com a presente situação, foi incluida nessa publicação uma análise retrospectiva, abrangendo um período de quinze anos, na qual são comparados levantamentos correspondentes a três diferentes épocas eqüidistantes: 1944, 1951 e 1959 .

Para facilitar a interpretação dos dados e corrigir as possibilidades de êrro, foram reduzidos $25 \%$ na tonelagem total correspondente a 1944, a fim de que o resultado obtido representasse mais aproximadamente, apenas a produção desembarcada em Santos.

Ficou então atribuido àquele período, um movimento geral da ordem de 7.068 toneladas, perfeitamente ajustável ao trabalho das 80 embarcações motorizadas que compunham a frota pesqueira da época, a maioria delas de pequeno porte e raio de ação.

O quadro demonstrativo abaixo, oferece uma idéia das transformações ocorridas nos referidos quinze anos, confrontando-se o número de barcos, em cada período assinalado com os respectivos volumes de desembarque.

\begin{tabular}{|c|c|c|c|c|c|c|}
\hline Anos & $\begin{array}{c}\text { No de } \\
\text { barcos }\end{array}$ & $\begin{array}{c}\text { Aumento de } \\
\text { unidades } \\
\text { No }\end{array}$ & $\begin{array}{c}\% \text { de } \\
\text { Aumento }\end{array}$ & $\begin{array}{c}\text { Desembarques } \\
(\mathrm{t})\end{array}$ & $\begin{array}{c}\text { Diferença } \\
(\mathrm{t})\end{array}$ & $\begin{array}{c}\% \text { de } \\
\text { Aumento }\end{array}$ \\
\hline 1944 & 80 & - & - & $7.068,0$ & - & - \\
1951 & 171 & 91 & 113,7 & $9.654,0$ & $2.585,0$ & 36,5 \\
1959 & 237 & 66 & 72,1 & $16.104,0$ & $6.450,0$ & 66,8 \\
\hline
\end{tabular}

$\mathrm{V}$ - DISCUSSÃO

A apreciação das Tabelas I e II põe em destaque os resultados obtidos recentemente, pelo recrutamento de embarcações estrangeiras de maior envergadura, equipadas convenientemnte. Embora, há pouco iniciadas, suas atividades já se fazem notar, 
não só pelo aumento geral de produção proporcionado, como também, por terem promovido os primeiros desembarques no pôrto de Santos, de espécies até então completamente desconhecidas em nosso mercados, tais como: albacoras, atuns e espadartes. A ocorrência dêsses peixes em boa quantidade e com relativa freqüência, representa sem dúvida, uma nova fase de desenvolvimento atingida pela indústria pesqueira no País, graças à aplicação racional e em maior escala dos engenhos de captura do tido linha e espinhel ("long-line").

Alias, em outro tipo de pesca com rêde de "trawl" de parelha, os resultados obtidos pelas unidades estrangeiras, foram também, bastante satisfatórios, em virtude da maior possibilidade de localização dos cardumes através de ecosondas e superior rendimento dos aperfeiçoados aparelhos de arrasto por elas utilizados. Tais resultados, entretanto, tiveram menor expressão que os obtidos pelos "atuneiros", pois êstes últimos operam em zonas totalmente novas, onde atingiram até 800 milhas mar a dentro, enquanto que as parelhas limitaram-se à exploração de fundos conhecidos da costa sul do País, em zonas onde há alguns anos vêm operando determinados barcos nacionais.

A Tabela III, seleciona pela ordem, as dez espécies ou variedades mais importantes, em têrmos de pêso e respectiva porcentagem nos três períodos: 1944, 1951 e 1959.

Analisando-a, encontramos inicialmente, a variedade conhecida como sardinha-verdadeira, liderando, em volume, os desembarques correspondentes aos três levantamentos, muito embora sua produção tenha decrescido gradativamente. No mesmo espaço de tempo verificou-se também, uma queda progressiva bastante acentuada, na porcentagem de sua participação conjunta. Entretanto, isto se deve mais ao fato de terem aumentado sobremaneira as descargas de outros peixes, do que à menor descarga da espécie apontada.

$\mathrm{Na}$ verdade, a produção atribuida à sardinha-verdadeira, jamais representou o volume real de sua captura, uma vez que, uma grande parte de sua produção, sempre foi desviada, para as indústrias de conserva instaladas dentro ou fora do Estado.

As espécies de fundo, capturadas com rêdes de arrasto (corvina, pescada, goete, camarões e etc.) cujas áreas de maior concentração se situam na costa sul do País, tiveram seus desembarques consideràvelmente melhorados em volume e qualidade, com o decorrer dos tempos. Sendo que, o significativo aumento verificado em 1959 revelou mais uma tendência de nossa pesca, nos últimos anos, ou seja: caminhar na direção sul com rêdes tipo "trawl". 
A manjuba, variedade que ocorre em grande escala no rio Ribeira do Iguape, foi incluida na relação de 1951 . Êsses desembarques, porém, não representam qualquer esfôrço da frota motorizada, considerando-se ser a pesca dêsses engraulídeos realizada através de canoas a remo, utilizando rêdes do tipo "arrastão de praia”. A participação dos barcos ficou limitada ao transporte até o pôrto de Santos. O maior volume de sua produção, entretanto, é industrializado na própria região.

As demais alterações encontradas na Tabela III, em cada período, deverão ser atribuidas ao maior desenvolvimento e conseqüente evolução da pesca. Existem no entanto outros fatôres, alguns até alheios às operações de captura pròpriamente ditas, capazes de terem influido para modificar a posição estatística de alguns peixes. Estão neste caso incluidas, por exemplo, as variedades: tainha, oveva e galo, cuja presença na relação de 1944, não foi confirmada nos outros dois anos em estudo.

$\mathrm{O}$ que poderia ter contribuido para a diminuição do volume de desembarque das referidas variedades, além da influência natural resultante do aumento verificado na captura de outras seria, individualmente:

a) Tainha - Como foi anteriormente esclarecido, em 1944 tôda a pesca nacional era controlada pela Comissão Executiva da Pesca. A produção dos núcleos litorâneos então formados, inclusive de tainhas capturadas nos cercos (currais) existentes nas cidades de Peruíbe, Itanhaem, Bertioga e adjacência, era incluida na produção de Santos.

A partir de 1946, com a extinção da C.E.P., aquela produção passou a ser exportada diretamente, sem possibilidade de contrôle. Talvez por isso, e não pròpriamente porque tenha havido menor ocorrência, a tainha deixasse de figurar entre as dez primeiras espécies, em volume de desembarque, nos períodos seguintes.

b) Oveva - O elevado preço alcançado pela variedade classificada como "mistura", nos últimos tempos, justificou a inclusão entre os seus componentes de alguns peixes de relativo valor comercial, inclusive a oveva, cujo desembarque passou a ser feito também, como integrante da mistura. Em 1944, sua descarga e venda se processava isoladamente, motivo pelo qual figurava com destaque no movimento estatístico.

c) Galo - Dois são os fatôres a considerar, com relação a esta variedade:

1. ${ }^{\circ}$ - tal como a oveva o total trazido pelos barcos foi sendo incluido na "mistura"; 


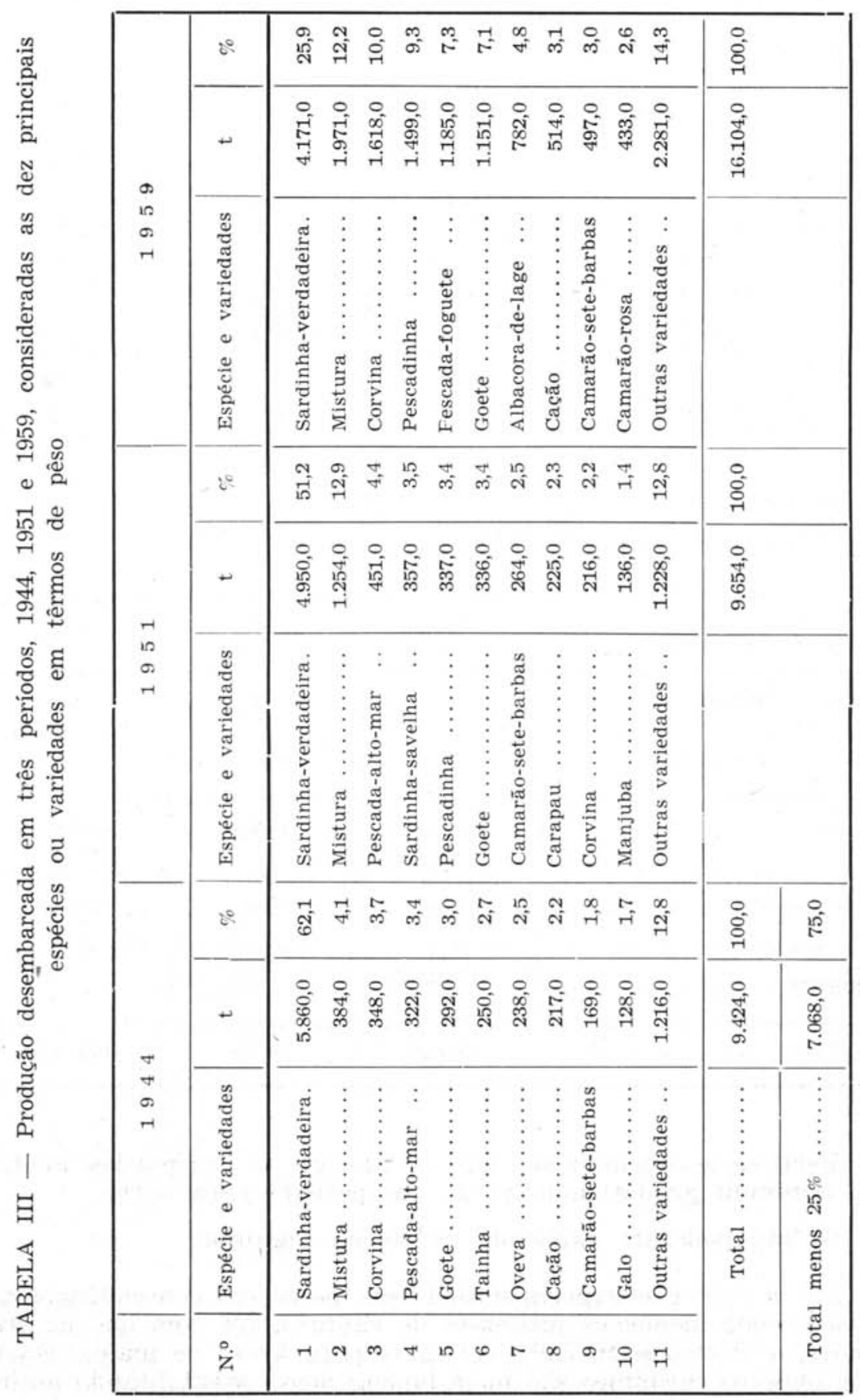


$2 .^{\circ}$ - a maior parte de seus desembarques em Santos, em 1944, provinha, por via marítima, de "cercos flutuantes" localizados em volta da ilha de São Sebastião. Extinta a C.E.P., a produção dos referidos cercos passou a ser quase que totalmente negociada naquelas imediações.

Comparando-se (Tabela III, Fig. 4) o volume de desembarque por variedade nos três períodos, verificamos que em 1959, seis unidades atingiram total superior a mil toneladas, enquanto que em 1951 sòmente duas e apenas uma em 1944, ultrapassaram aquêle pêso, mesmo assim, através de variedades de reduzido valor comercial. Êste fato, aliás, bastante significativo, salienta mais uma das tendências de nossa pesca atual, ou seja, a de melhorar o volume e a qualidade dos desembarques, pela exploração de áreas mais distantes e produtivas, utilizando barcos de maior envergadura.

Os três períodos poderão ser comparados, ainda, com relação aos desembarques por categoria:

\begin{tabular}{|c|c|c|c|}
\hline & 1944 & 1911 & 1959 \\
\hline No de variedades anotadas. & 106 & 99 & 73 \\
\hline Grupos & \multicolumn{3}{|c|}{ Tonela das } \\
\hline Peixes $\quad \ldots \ldots \ldots \ldots \ldots \ldots \ldots \ldots$ & $6.852,0$ & $9.206,0$ & $15.097,0$ \\
\hline Crustáceos $\ldots \ldots \ldots \ldots \ldots \ldots$ & 213,0 & 444,0 & $1.000,0$ \\
\hline Moluscos ... & 3,0 & 4,0 & 7,0 \\
\hline Total $\ldots$. & $7.068,0$ & $9.654,0$ & $16.104,0$ \\
\hline
\end{tabular}

Verifica-se inicialmente que o número de variedades anotadas, diminuiu gradativamente de um período para outro.

$O$ fato pode ser explicado da forma seguinte:

a) a evolução experimentada pela pesca em conseqüência de novos e mais modernos processos de captura, fêz com que as atividades se deslocassem cada vez mais para áreas de maior densidade, onde os cardumes são mais homogêneos, possibilitando assim 


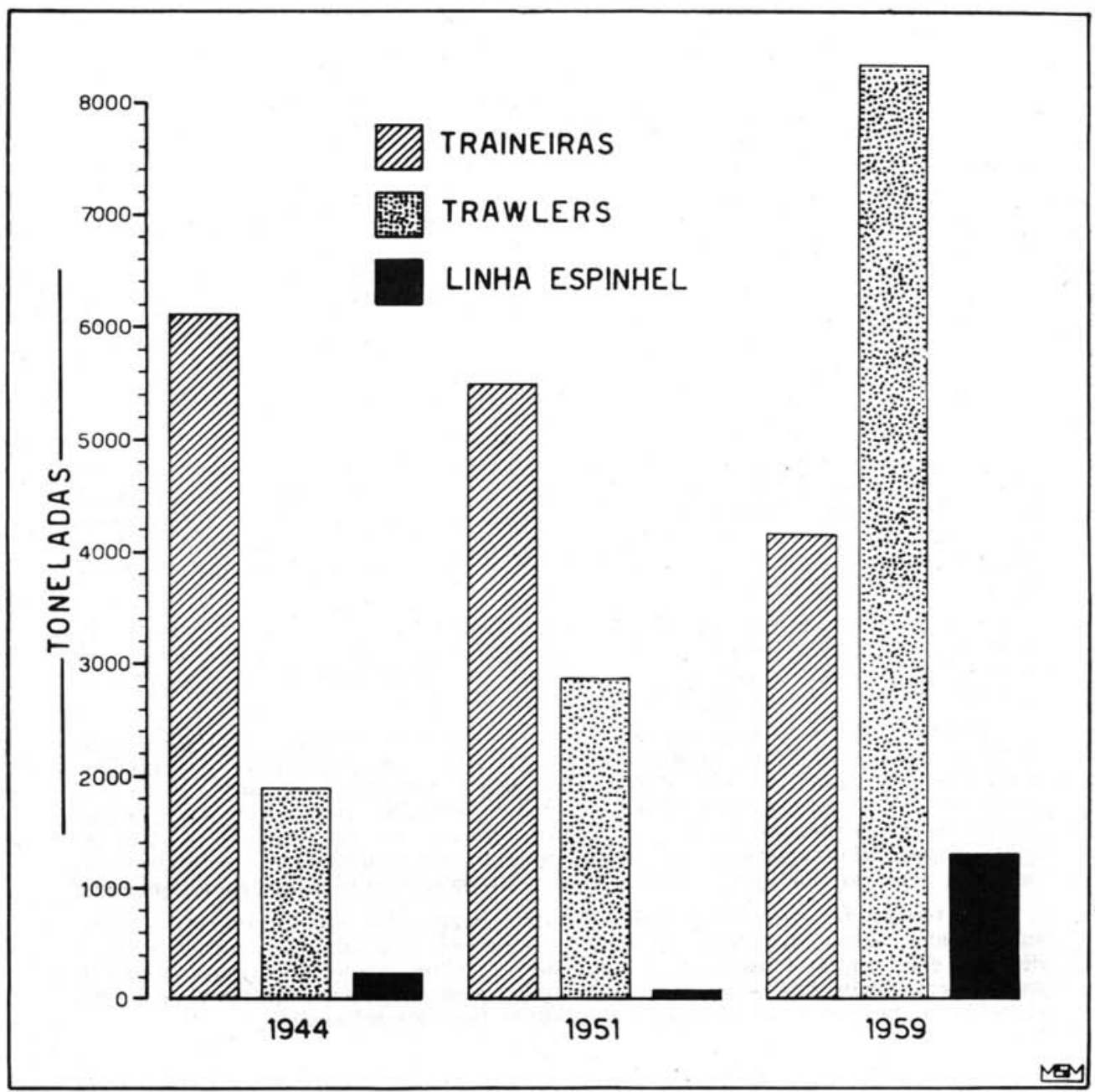

Fig. 4 - Estudo comparativo dos desembarques por aparêlho de captura num espaco de 15 anos, considerando três periodos eqüidistantes. Verifica-se um comportamento inverso entre as rêdes de superficie (traineiras) e os aparelhos de fundo («trawlers»). As traineiras sofreram queda gradativa, enquanto os «trawlers» tiveram aumento sempre crescente. A pesca em linha e espinhel sòmente teve alguma significação em 1959. 
descargas maciças de determinadas espécies. Há quinze anos, isso era pràticamente impossível, pois as operações se realizavam quase exclusivamente na costa paulista, onde os estoques são bastante heterogêneos ;

b) como já assinalamos em outra oportunidade, alguns peixes de maior valor comercial, que em outros tempos eram desembarcados separadamente, hoje em dia estão incluídos na "mistura", para valorizá-la.

A seguir constatamos que o aumento verificado atingiu os três grupos, destacando-se o elevado índice alcançado pelo grupo dos crustáceos em 1959, quatro vêzes e meia superior ao volume de 1944 e duas vêzes e meia ao de 1951.

\section{VI - RESUMO}

O desenvolvimento das pesquisas sôbre a pesca iniciados em 1958 pelo Grupo de Pesquisas de Santos, veio encarecer a necessidade de aperfeiçoamento dos métodos de coleta de dados estatísticos existentes; isto porque, os levantamentos iniciados em 1950 não permitiam uma estatística detalhada, devido a carência de material e pessoal especializado, que comprometiam a sua continuidade.

Atualmente, melhor assistidas e orientadas, as pesquisas atingiram setores mais avançados, motivo pelo qual, a tarefa de obtenção de dados com informações precisas, capazes de garantir a autenticidade dos resultados, adquiriu maior responsabilidade.

Pela análise e apreciação dos dados coligidos no presente trabalho, verificou-se que a indústria pesqueira no Estado, vem evoluindo lentamente, desde 1944, através de seus próprios recursos (Braga \& Moraes, 1952). A partir de 1958, sofreu uma favorável transformação, resultante do recrutamento de embarcações nacionais e estrangeiras, de maior porte e raio de ação, cujas características de funcionamento e produtividade, proporcionaram-lhe, sem dúvida, uma fase de desenvolvimento nunca dantes alcançadas.

As tendências reveladas indicam um progressivo afastamento das capturas para áreas distantes e mais produtivas; na direção norte, mar a dentro, com linha e espinhel ("long-line") e no rumo sul, mais junto à costa, com rêdes tipo "trawl". Tais operações, tiveram significativa participação na melhoria do volume e qualidade dos desembarques.

\section{VII - SUMMARY}

The development of programs of research on marine fisheries begun in 1958 by the Santos group have drawn attention to the necessity of improvement of methods of collecting fishery statistics; although the collections were originally started in 1950, the early years' work were not a high standard, partially due to the high cost of personnel and means. Now, the research is becoming more exacting in its statistical requirements.

It may be seen, from the analysis of data presented in this paper, that the São Paulo fishery has been evolving slowly, depending mostly on its own resources. Beginning in 1958, there was a "revolution", the result of 
adding to the fleet larger vessels, both Brazilian and foreign, which have raised the fishing activities to a level never before achieved.

The general tendencies are for fishing in more distant and more productive waters both to the north with long-lines and along the coast to the south with trawls, and the effects of these tendencies have been increases in both the volume and quality of the fishery products landed.

\section{VIII - AGRADECIMENTOS}

Desejamos externar nossos agradecimentos à FAO, pela cooperação recebida do seu corpo técnico e aos funcionários do Serviço do Pescado, da Divisão de Proteção e Produção de Peixes e Animais Silvestres, do Departamento da Produção Animal da Secretaria da Agricultura, pela eficiente colaboração prestada.

\section{IX - BIBLIOGRAFIA}

Braga, A. \& Moraes, J. R.

1952. Considerações sôbre a produção pesqueira marítima no Estado de São Paulo. Bol. Ind. Animal, n. ${ }^{\circ}$ 1-3.

RIPLEy, W. E.

1956. Relatório ao Govêrno do Brasil sôbre biologia da pesca. Relatório $\mathrm{FAO} / \mathrm{ETAP}, \mathrm{n}^{\circ} 494,23$ p. Roma, FAO.

Vieira, B. B. et al.

1945. Anuário da pesca marítima no Estado de São Paulo: 1944. São Paulo, Secr. Agr., Dep. Prod. Animal. 122 p. 
-

รอวงอา อp $\circ \cdot \mathrm{N}$

eased op seic

Ẹ̣uģsne ap sẹa

оระaวaว

ossas8ay

epjes

OONกJ OO. IYN

javalannjoda

造 jovaranioda

u. V1500 '15ia

势

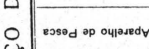

\&)

viyogatro 


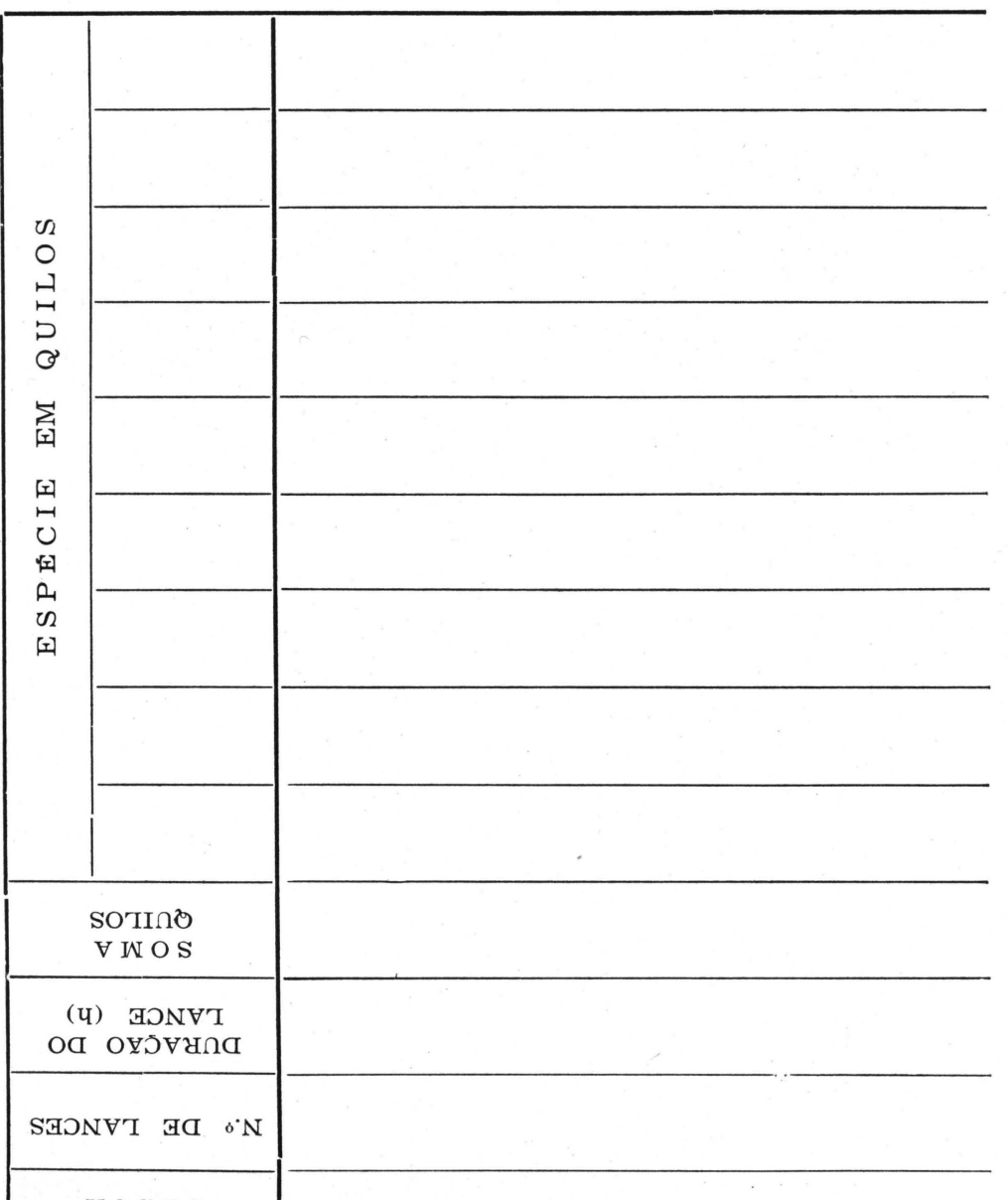

\begin{tabular}{|c|c|c|c|}
\hline & \multirow{8}{*}{ 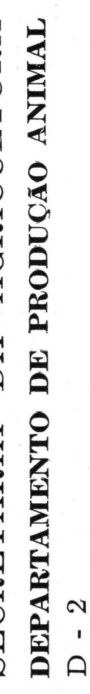 } & \multirow{8}{*}{ 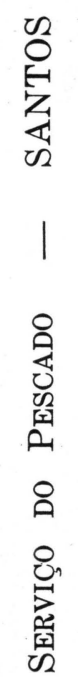 } & \multirow{2}{*}{ 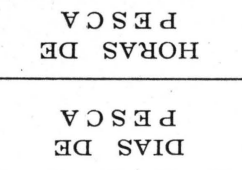 } \\
\hline & & & \\
\hline & & & $\begin{array}{l}\text { VIDNGSAH } \\
\text { HA SHIC }\end{array}$ \\
\hline & & & 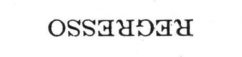 \\
\hline & & & $\mathrm{V} \propto \mathrm{I} \mathrm{VS}$ \\
\hline & & & 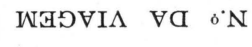 \\
\hline & & & оว О Т Я \\
\hline & & & $\mathrm{S} \forall \mathrm{I} \propto$ \\
\hline
\end{tabular}




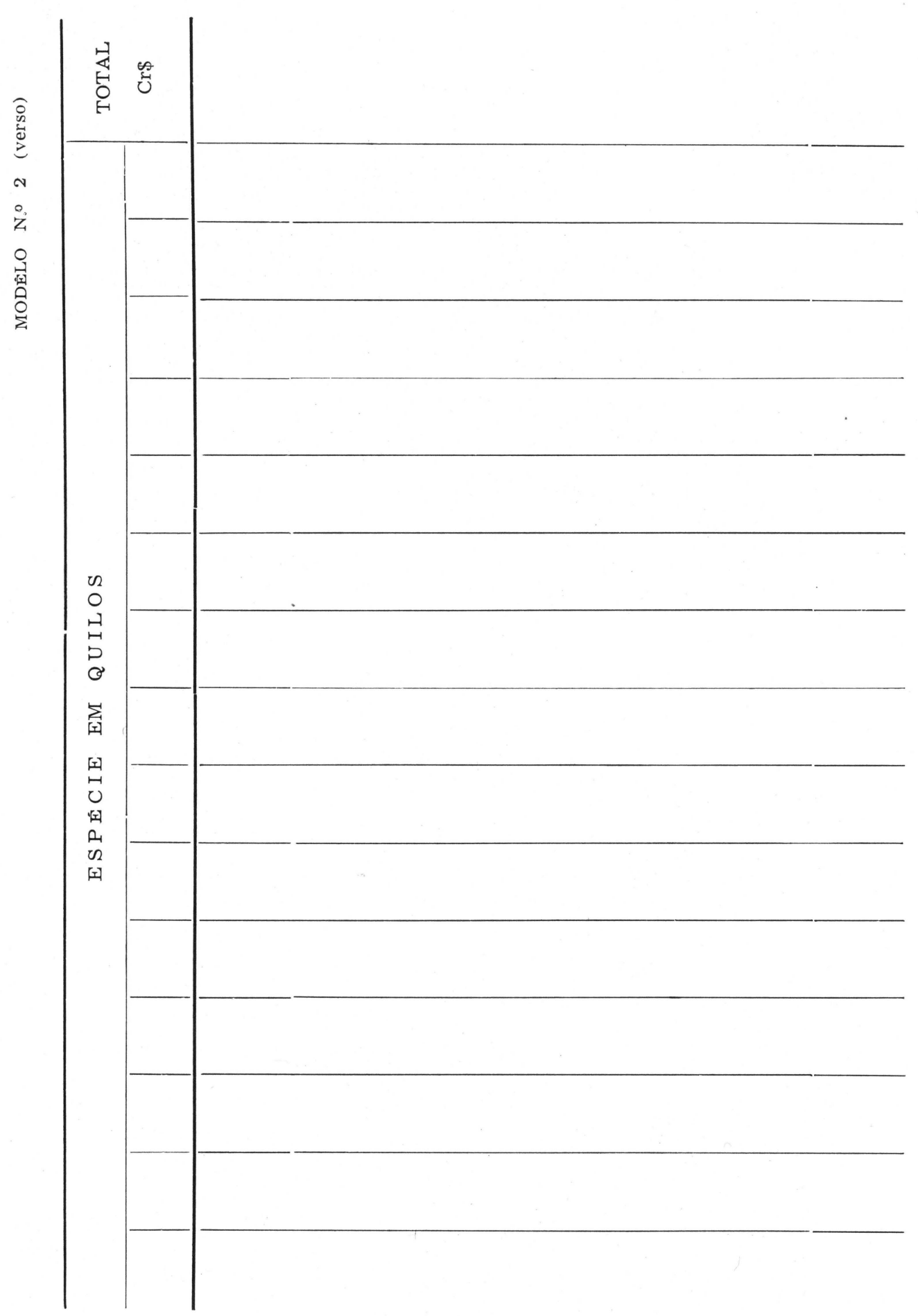

